\title{
Endoscopic Excision of A Fibroadenoma Breast: Trans Axillary Approach
}

\author{
Adhikary $S,{ }^{1}$ Sood $S,{ }^{1}$ Dhungel $K,{ }^{2}$ Rajbanshi $S,{ }^{1}$ Shakya $V,{ }^{1}$ Khaniya $\mathrm{S}^{1}$
}

\author{
${ }^{1}$ Department of Surgery \\ ${ }^{2}$ Department of Radiology \\ BP Koirala Institute of Health Sciences, Dharan, \\ Nepal.

\section{Corresponding Author} \\ Shailesh Adhikary \\ Surgical Discipline \\ BPKIHS, Dharan, Nepal \\ Email:
}

Citation

Adhikary S,Sood S, Dhungel K, Rajbanshi S, Shakya V, Khaniya S. Endoscopic Excision of A Fibroadenoma Breast: Trans Axillary Approach. Kathmandu Univ Med J 2012;38(2):106-108.

\begin{abstract}
Benign breast lumps affect $10 \%$ of females in their lifetime. Surveillance, assurance, medications and surgical excision are options available to surgeons. Avoiding scars on the breast is an inherent feminine desire. Numerous minimal invasive approaches have evolved due to this concern. The time honoured circumareolar incisions camouflages the scar to a large extent, yet the incision still remains on the breast tissue and unfortunately the scar undergoes the same old sequelae as with any other scars both aesthetically or psychosocially. The close by anatomical space; axilla provides an easy access for endoscopic breast surgery. We utilized this area and applied our expertise to remove a fibroadenoma in a teenager which spared her breast from the scar. The technique was safe and effective. It conserved aesthetics and led to a better compliance.
\end{abstract}

\section{KEY WORDS}

breast lump, endoscopic breast surgery

\section{INTRODUCTION}

Minimal invasive surgery has advanced so much due to its appeal of low morbidity, early resumption of work and activity apart from pain and better aesthetic results. Aesthetics is of high importance to any young girl or a female especially when it concerns their breasts. ${ }^{1}$ They would like to avoid the scalpel. Axilla, an anatomical contiguous space, provides surgical access to breast. ${ }^{2}$ The case is presented with a literature review highlighting the benefits of an endoscopic procedure and some limitations of the traditional circumareolar incisions.

\section{CASE REPORT}

A teenage girl presented at our hospital with a painless breast lump in the upper medial quadrant for one year was evaluated with a proper history and a good clinical and ultrasound imaging of both the breasts. The scan reported a well-defined lesion in the upper medial quadrant and she was consented for a minimally invasive procedure.

\section{Technique}

After a proper communicaton with the patient and the written informed consent the surgical procedure was performed as following.

Position of the patient: Supine with ipsilateral upper limb abducted and extended so that the arm lied on the side of the patient's head. The side to be operated was elevated with a sand bag underneath the scapula and the operating table tilted up by 20 - 30 degrees. Port Placements: A 10 $\mathrm{mm}$ port in the mid axillary line at a level just above the nipple and two $5 \mathrm{~mm}$ ports along the anterior axillary fold two finger breadths above and below the first port (Fig 1). The $10 \mathrm{~mm}$ port was introduced through the skin incision and advanced towards the breast staying superficial to the muscles of the anterior axillary fold. The advance towards the breast from the periphery was guided by palpation of trocar in the subcutaneous plane and the lump was stabilized by the left hand of the surgeon. The breast tissue 


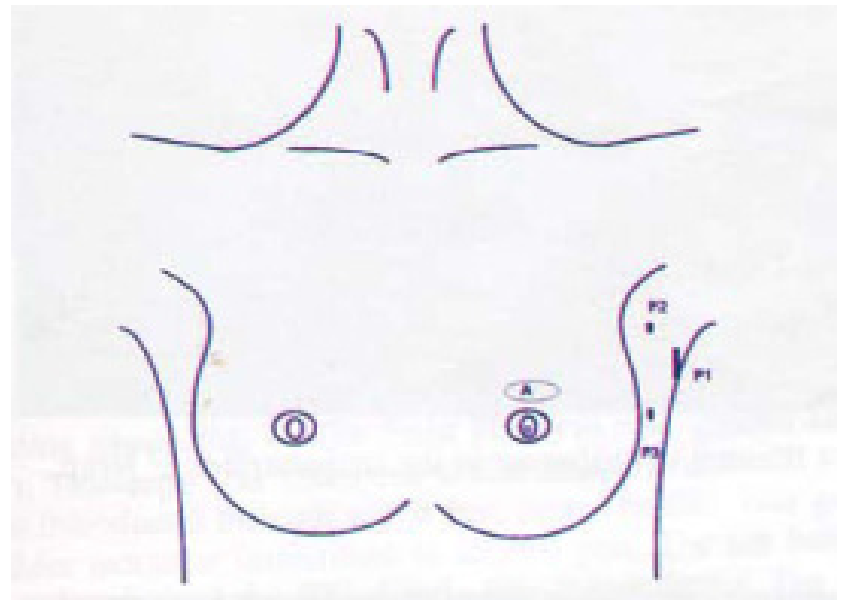

Figure 1. Breast sketch showing different port placements.

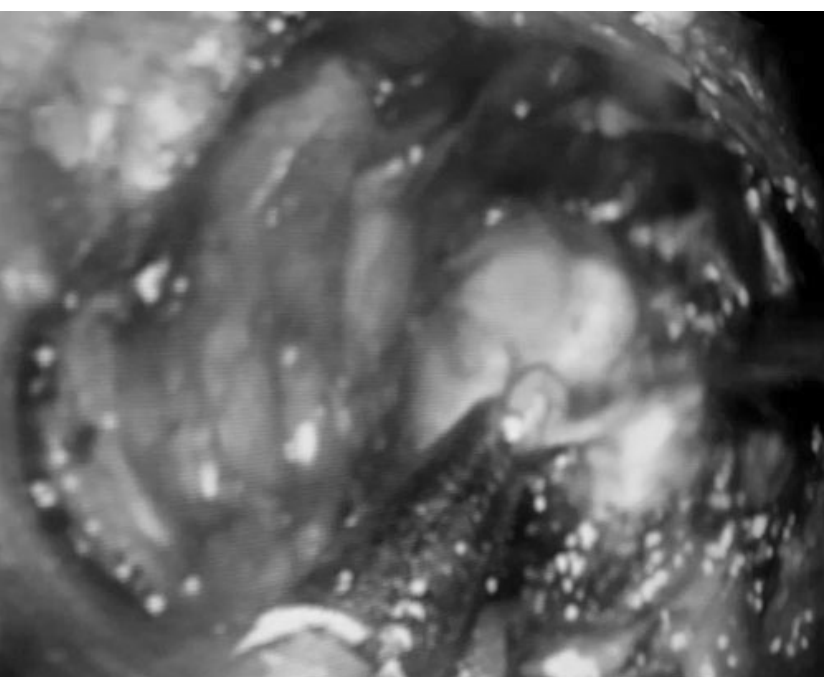

Figure 2. Endoscopic excision in progress.

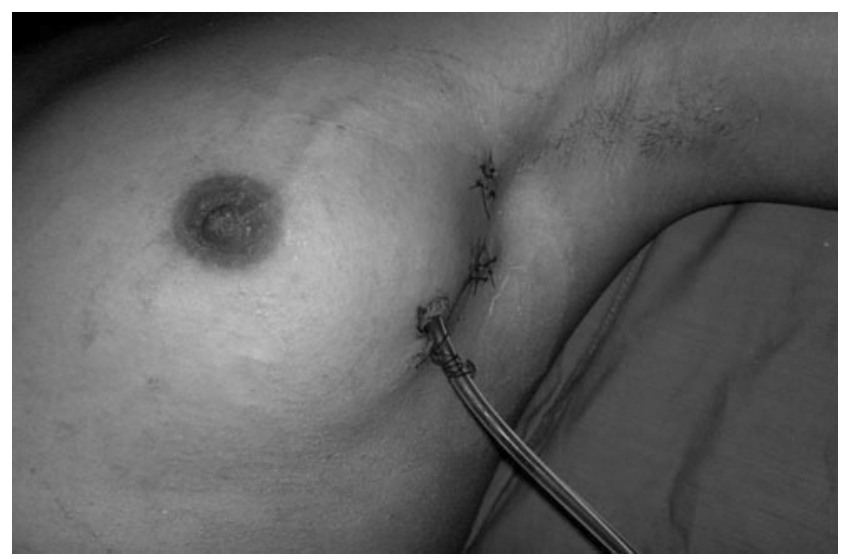

Figure 3 . The axillary space after excision.

was entered for about 2- $3 \mathrm{cms}$. The trocar was removed and the sheath connected to the gas for insufflation and the 0 degree scope introduced. The space for access was then made by sweeping and darting movements of the telescope through the avascular loose areolar tissues like we do for a extraperitoneal space creation in a groin hernia repair. Once an adequate space was created two other $5 \mathrm{~mm}$ ports were made; two finger breadths above and below the $10 \mathrm{~mm}$ port. Subsequently, the dissection was done all around the lump with the use of a monopolar electrocautery (Fig 2). Once the lump was made free it was pulled towards the axilla and the $5 \mathrm{~mm}$ scope introduced through one of the $5 \mathrm{~mm}$ port and finally the lesion was removed through the $10 \mathrm{~mm}$ port with the help of a extractor. The haemostasis was checked and a compression bandage done after dressing. The breast was assessed the next morning for any bogginess, and the patient was discharged from the hospital on the second day with an advice to resume: Activity, Baths, Committment, Diet, Exercise. During her follow up visits she remained satisfied in terms of pain, comfort level and scars.

\section{DISCUSSION}

Breast is an integral part of any lady's self-esteem. There is more than $10 \%$ chance of developing a benign lump in a female in her lifetime. ${ }^{3}$ Non operative surveillance is one option. Numerical expression and communication of risks in this ailment is not at all easy for clinicians. ${ }^{4}$ Better social awareness of the risks associated with breast lump and the risk of communicating have made conservative approaches perhaps less practical. ${ }^{4}$ Majority of breast lumps are surgically excised. In our society a young female with a breast disease must get treated or she would invite the ire of her husband. Cosmetic result is of paramount importance in breast surgery. Application of a circumareolar incision is a testimony to it. Proponents of endoscopic procedures argue that aesthetics of circumareolar incisions are far from being satisfactory. It is evident from many modifications suggested viz. cryoablation, radiofrequency assisted and ultrasound guided excisions which have attempted to improve upon conventional incisions. ${ }^{3,5,6}$ Though less invasive than open surgery they have not eliminated the scar from the breast and these procedures have their own complications and limitations. ${ }^{3,5,6}$ Commercialization of circumareolar silicon patches to reduce the scars is based upon a feminine desire to make the breast scar free. ${ }^{7}$ Apart from the aesthetics, scars on the breast are never good even from a surgeon's perspective. These scars are an independent risk factors for malignancy. ${ }^{8}$ They are painful during lactation, have a tendency to stretch and become hypertrophic too. ${ }^{2,9,10}$ In view of all these issues; making an attempt to remove the pathological target tissue from an adjacent area may be a better alternative to a customary circumareolar incision. ${ }^{2}$ Axilla though not a natural orifice provides an anatomical contiguous area for creating an access. This echoes the same sentiments as addressed by the excitement associated with the emergence and evolution of NOTES (Natural Orifice Transluminal Endoscopic Surgery). ${ }^{11}$

Transaxillary approach has been tried in an anecdotal manner. ${ }^{1}$ Osanai et al have reported a similar approach but with an extensive dissection of retromammary space and they also emphasized the need to take care of some perforators as well. ${ }^{2}$ In our technique we dissected along the avascular planes and limited our dissection to the 
area around the lesion. Risk of insult to the axilla was eliminated by staying above the anterior axillary fold. It was substansiated by abscence of any axillary or upper limb deformity. the patient had some pain on the port site which required paracetamol tablets and was discharged the next morning with a suction drain in place.

\section{CONCLUSION}

The endoscopic breast lump excision is technically safe.

2. Osanai T, Nihei Z, Ichikawa W, Sugihara K. Endoscopic resection of benign breast tumours. Surg Laparos and Endosc Perctan Tech 2002;12: 100-03.

3. Kaufman CS. Office based cryoablation of breast fibroadenomas with long term follow up. Breast J 2005;11:344-50.

4. Elmore JG, Gigerenzer G Benign breast disease. The risks of commmunicating risks. N Eng J Med 2005;353:297-9.

5. Fine RE, Staren ED. Percutaneous radiofrequency assisted excision of fibroadenomas. Am J Surg 2006;192:545-7.

6. Iwuagwu OC. Ultrasound guided minimal invasive surgery for fibroadenomas. Arch Surg 2004;139:564.

7. Hatfield AS,Gryskiewicz JM. "Zigzag" wavyline periareolar incision. Plast Reconstruct Surg 2002;110:1778-83.

8. Jacobs TW, Byrine C, Colditz G Conolly Jl, Schimdt SJ. Radical scars in benign breast biopsy specimens and the risk of breast cancer. $N$ Eng
Scars are avoided on the breasts, it is a patient friendly procedure, and is a true key hole surgery, so the surgeons should include it in their repertoire as it justifies the adage "Surgery leaves scar not only on the body but on the mind as well". Nonetheless, we need to conduct a randomized controlled trial to reach an authentic inference.

\section{REFERENCES}

1. Kitamura K. Transaxillary approach for the endoscopic extirpation of benign breast tumors. Surg Laparos and Endosc 1988;8:277-9.

\section{J Med 1999;340:430-6.}

9. Fayman MS, Potgeoter E, Becker PJ. Outcome study: Periareolar mammoplasty patients' perspective. Plast Reconstruct Surg 2003;111:676-84.

10. Rojanamin S, Ratanawichitrasin A. Limited incision with plastic bag removal of a large fibroadenoma. Br J Surg 2002;89:797.

11. Swanstrom LL. Current technology development for natural orifice transluminal endoscopic surgery. Cir Esp 2006;80:283-8. 